\title{
ANÁLISES PRELIMINARES DE SUBSTÂNCIAS VISCOSAS EM ESPECTRÔMETRO DE INFRAVERMELHO UTILIZANDO SUPORTE ALTERNATIVO
}

\section{Analytical alternative method applied to viscous substances by infrared spectrometry}

\author{
Lillian A. Soares ${ }^{1}$; Eric de S. Gil'; Kênnia R. Rezende ${ }^{2^{*}}$ \\ 1,2 Mestranda do Programa de Pós-Graduação em Ciências Farmacêuticas - Faculdade de Farmácia, \\ Universidade Federal de Goiás, Goiânia, GO, Brasil \\ ${ }^{2}$ Laboratório de Biofarmácia e Farmacocinética de Produtos Naturais e Sintéticos Bioativos - Faculdade de \\ Farmácia, Universidade Federal de Goiás, Goiânia, GO, Brasil
}

* Autor para correspondência: kennia@farmacia.ufg.br

Recebido em 09/11/2006 - Aceito em 13/12/2006

RESUMO: A espectrometria de infravermelho é uma técnica amplamente utilizada na identificação de compostos orgânicos. Porém, tais análises são dificultadas pelo custo relativamente elevado de acessórios adequados às características físico-químicas destas. Neste trabalho, investigou-se um procedimento alternativo para análises qualitativas de substâncias viscosas em espectrômetro de infravermelho, utilizando-se um filme de PVC como base suporte das amostras. Foram feitas análises comparando-se os espectros de amostras de lanolina e vitamina $\mathrm{E}$ em filme de PVC e com pastilhas de $\mathrm{KBr}$, bem como com dados da literatura. Os resultados demonstraram vantagens da metodologia proposta como a simplicidade, o baixo custo e a rapidez, além da obtenção de espectros robustos.

PALAVRAS-CHAVE: infravermelho, substâncias viscosas, filme de PVC.

ABSTRACT: Infrared spectroscopy is a very used technique for structural elucidation of organic compounds. However, some accessories used on sample preparation are somehow expensive. In this work, it was investigated an alternative procedure for qualitative analysis of viscous substances using PVC film like support. Analysis of lanolin anhydrous and vitamin $\mathrm{E}$ were realized in $\mathrm{KBr}$ discs and $\mathrm{PVC}$ film comparatively to literature. The main advantages of this method rely on running samples spending less time, at low-cost support cell obtaining confident spectra.

KEYWORDS: Infrared spectroscopy, viscous substances, PVC film.

\section{INTRODUÇÃO}

A espectrometria é o processo analítico-instrumental baseado nas propriedades de absorção, emissão e reflexão de energia eletromagnética em região específica do espectro (PAVIA, 1996; SILVERSTEIN, 1987). A espectroscopia de infravermelho (IV) compreende a região do espectro eletromagnético de comprimentos de onda variando de 0,75 a $1000 \mu \tilde{m}$. A região do infravermelho entre 2,5 e 14,9 $\mu \mathrm{m}\left(670\right.$ a $\left.4000 \mathrm{~cm}^{-1}\right)$ concentra o maior interesse dos químicos, embora as regiões do infravermelho próximo $(0,75$ a $2,5 \mu \mathrm{m})$ e do infravermelho distante $(14,9$ a $50 \mu \mathrm{m})$ venham angariando maior atenção. Absorções de energia desta magnitude, provocam perturbações nas freqüências específicas das diferentes ligações químicas. Ou seja, a freqüência de cada ligação corresponde a um nível vibracional e depende da superfície de energia potencial da molécula, da geometria molecular, das massas dos átomos e eventualmente do acoplamento vibrônico. Deste modo, grupos funcionais distintos apresentaram absorção com intensidade e em regiões distintas do espectro (Tab.1), fazendo da espectrometria de infravermelho, uma metodologia bastante útil na identificação de compostos orgânicos (MILMAN, 2006; SKOOG, 2002).

A partir de 1980 a técnica de infravermelho evoluiu bastante, destacando-se a substituição gradual de espectrômetros dispersivos, por espectrômetros com transformada de Fourier (FTIR) e o desenvolvimento de aplicações na região do infravermelho próximo e distante (Tab. 2) (KAROUI, 2006; BODECCHI, 2005; BAULSIR, 
1996). A criação de vários acessórios viabilizou a aplicação do IV a amostras sólidas, líquidas e gasosas. Além da prensa hidráulica, a confeç̧ão de pastilhas de $\mathrm{KBr}$ pode ser realizada com utilização de molde evacuável, almofariz e pistilo (idealmente de ágata) além de outros acessórios úteis em rotinas de controle de qualidade, como as células desmontáveis para líquidos e materiais viscosos, células seladas para líquidos, células para gases, cartões de amostras, kit para produção de filmes de polímeros, etc (SKOOG, 2002; VOGEL, 2002; WHO, 1997; SILVERSTEIN, 1987; HINITZ, 1970).

Tabela 1- Faixas de absorção e intensidade relativa para diferentes grupos funcionais

\begin{tabular}{lcl}
\hline Grupo Funcional & $\begin{array}{c}\text { Faixa de Absorção } \\
\left(\mathbf{c m}^{-1} \mathbf{)}\right.\end{array}$ & Intensidade \\
\hline $\mathrm{N}-\mathrm{H}$ & $3500-3300$ & Fraca a forte \\
$\mathrm{O}-\mathrm{H}$ & $3650-2700$ & Variável alargada \\
$\mathrm{C}-\mathrm{H}$ & $3200-2800$ & Média a forte \\
$\mathrm{C} \equiv \mathrm{C}$ & $2300-2100$ & Fraca \\
$\mathrm{C} \equiv \mathrm{N}$ & $2300-2200$ & Forte \\
$\mathrm{C}=\mathrm{C}$ & $1600-1500$ & Variável \\
$\mathrm{C}=\mathrm{O}$ & $1760-1690$ & Forte \\
$\mathrm{C}-\mathrm{X}$ & $1100-550$ & Média a fraca \\
\hline
\end{tabular}

Tabela 2 - Principais aplicações da espectrometria no infravermelho

\begin{tabular}{llll}
\hline Região & Técnica & Tipo de Análise & Tipo de Amostra \\
\hline IV próximo & Reflexão difusa & Quantitativa & Misturas sólidas ou líquidas \\
& Absorção & Quantitativa & Misturas gasosas \\
IV médio & Absorção & Qualitativa & Compostos puros sólidos, líquidos \\
& Absorção & Quantitativa & Misturas complexas \\
& Reflexão & Qualitativa & Compostos puros sólidos ou \\
& Emissão & Quantitativa & Amouidos \\
& Aualitativa & Espécies puras inorgânicas ou \\
IV distante & Absorção & & organometálicas \\
\hline
\end{tabular}

Todavia, o custo para aquisição de todos estes acessórios é relativamente alto, fato que muitas vezes inviabiliza a realização de medidas de líquidos viscosos. Assim, neste trabalho investigou-se um procedimento alternativo, simples e de baixo custo para análise qualitativa de substâncias viscosas em espectrômetro de infravermelho, utilizando-se como suporte para amostras viscosas, o filme de PVC comercial. As vantagens do procedimento proposto são: a simplicidade, o baixo custo e a rapidez. Avaliações foram feitas comparando-se os espectros obtidos de amostras de lanolina e vitamina $\mathrm{E}$ em filme de PVC com pastilhas de $\mathrm{KBr}$ bem como com dados da literatura.

\section{MATERIAL E MÉTODOS}

\section{Preparo das pastilhas de $\mathrm{KBr}$}

$\mathrm{O} \mathrm{KBr}\left(\operatorname{Vetec}^{\circledR}\right)$ foi previamente dessecado em estufa à $120^{\circ} \mathrm{C}$ até peso constante e triturado em almofariz de ágata .Posteriormente foram colocados $100 \mathrm{mg}$ do $\mathrm{KBr}$ no pastilhador seguido de compressão em prensa hidráulica Perkin Elmer ${ }^{\circledR}$ modelo 4037 com pressão de $10^{a}$ toneladas por 2 minutos, para obtenção das pastilhas finas e transparentes.

\section{Análise em Pastilhas de $\mathrm{KBr}$}

A amostra de lanolina anidra $\left(\right.$ Galena $\left.{ }^{\circledR}\right)( \pm 80 \mathrm{mg})$ e de vitamina e $\alpha$-tocoferol (Galena $\left.{ }^{\circledR}\right)$ foram colocadas sobre pastilhas de $\mathrm{KBr}$, com auxílio de uma espátula, até a obtenção de espessura fina $( \pm 2 \mathrm{~mm})$. As pastilhas obtidas foram inseridas no compartimento de leitura do Espectrômetro de Infravermelho BX/RX Perkin Elmer ${ }^{\circledR}$ (modelo 60508) e analisadas, obtendo-se os espectros de lanolina (Fig. 1B) e vitamina E (Fig. 2B). O equipamento 
foi mantido em sala com temperatura e umidade controladas. A faixa espectral utilizada compreendia números de onda entre 4000 e $400 \mathrm{~cm}^{-1}$, sendo utilizada resolução de $4 \mathrm{~cm}^{-1}$. O procedimento foi realizado em triplicata.

\section{Análise sobre filme de PVC}

Um pedaço de filme PVC comercial transparente (Rolopak, Alba Química S.A) íntegro, nas dimensões de $0,015 \mathrm{~mm}(\mathrm{e}) \times 2,0(\mathrm{I}) \times 2,0(\mathrm{~h}) \mathrm{cm}$ foi colocado no suporte para pastilhas do espectrômetro de forma a permanecer tensionado. Sobre este filme foram depositadas lanolina anidra ou vitamina E, com auxílio de uma espátula, até a obtenção de finas camadas da amostra $( \pm 2 \mathrm{~mm})$. Os espectros de infravermelho obtidos para a lanolina e vitamina $\mathrm{E}$ são apresentadas na Figura $1 \mathrm{~A}$ e $2 \mathrm{~A}$, respectivamente. $\mathrm{O}$ procedimento foi realizado em triplicata, no Laboratório de Controle de Qualidade de Medicamentos (LCQM) da Universidade Federal de Goiás.

\section{RESULTADOS E DISCUSSÃO}

Comparando-se os espectros de lanolina anidra (Fig. 1) sobre os suportes de pastilhas de $\mathrm{KBr}$, filme de PVC e com dados da literatura, observou-se estreita semelhança, evidenciada pela presença das seguintes bandas em (média $\mathrm{N}=3 \pm$ desvio padrão): $2923( \pm 1,0), 2853( \pm 1,2), 1737( \pm 2,1), 1464( \pm 1,0) \mathrm{cm}^{-1}$, o que mostra claramente que a técnica sugerida, com utilização de filme de PVC, parece não interferir na qualidade dos espectros obtidos (ALDRICH LIBRARY, 1985).
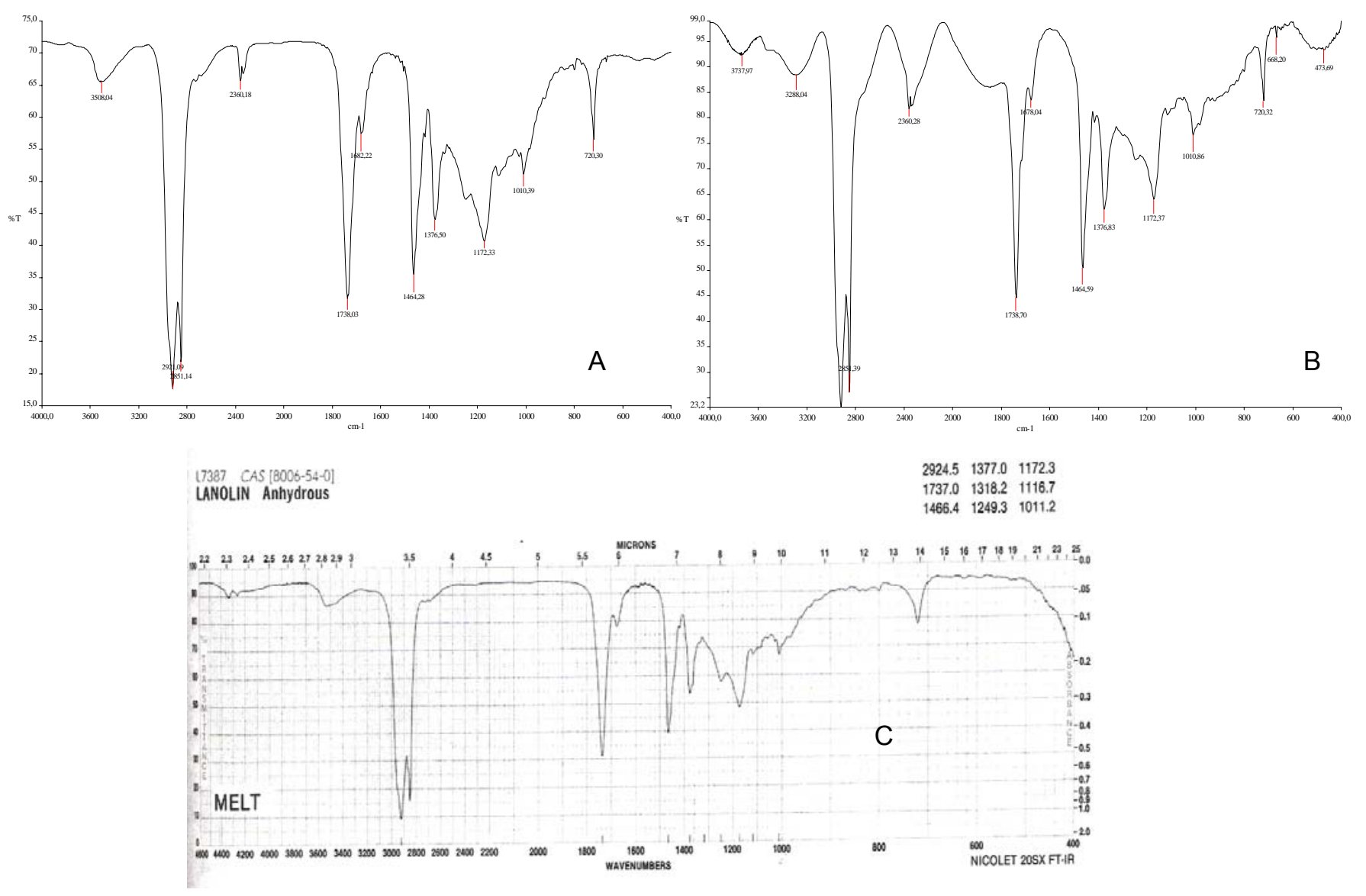

Figura 1: Espectros de IV de lanolina obtidos em filme de PVC (A), pastilhas de $\mathrm{KBr}(\mathrm{B})$ e dados da literatura ALDRICH LIBRARY, 1985 (C).

$\mathrm{Na}$ comparação dos espectros de vitamina E (Fig. 2) obtidos sobre os suportes de pastilhas de $\mathrm{KBr}$, filme de PVC e com dados da literatura não foram observadas diferenças significativas entre os espectros. Semelhanças podem ser observadas pela presença de bandas características em todas as análises $(\mathrm{N}=3 \pm \mathrm{dp})$ : 2927( $\pm 2,5), 1757( \pm 2,0), 1461( \pm 1,7), 1367( \pm, 02), 1209( \pm 2,0), 1010( \pm 1,0), 921( \pm 1,0) \mathrm{cm}^{-1}$. Assim, observa-se que a utilização do filme de PVC não interfere qualidade dos espectros obtidos. 

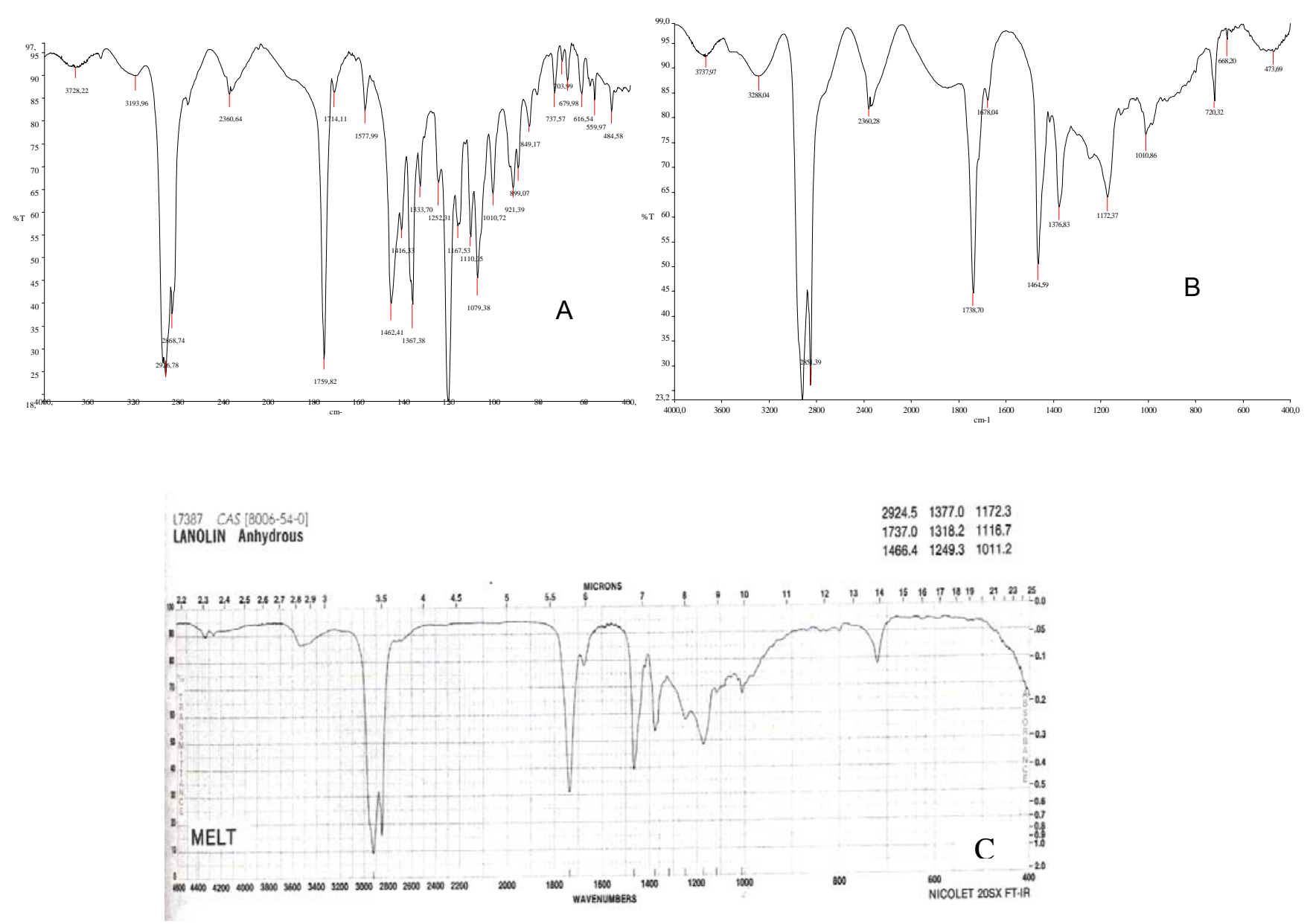

Figura 2. Espectros de IV de vitamina $E$ obtidos em filme de PVC (A); em pastilhas de $\mathrm{KBr}(\mathrm{B})$; e de dados da literatura ALDRICH LIBRARY, 1985 (C).

\section{CONCLUSÕES}

O preparo de substâncias viscosas em suporte de $\mathrm{KBr}$ raramente fornece discos de espessura homogênea demandando assim, elevado tempo de preparo. Alternativamente, a metodologia analítica desenvolvida neste trabalho possibilita a utilização de filme de PVC, pois o espalhamento e a obtenção de camadas delgadas das amostras são facilitados. Deste modo, tanto o preparo quanto a realização das análises são mais rápidas e com menor custo sem, no entanto, prejudicar a qualidade dos espectros obtidos.

\section{REFERÊNCIAS BIBLIOGRÁFICAS}

BAULSIR, C. F.; SIMLER, R. J. Design and evaluation of IR sensors for pharmaceutical testing. Advanced Drug Delivery Reviews, v. 21, issue 3, p. 191-203, 1996.

BODECCHI L. M., et al. Application of infrared spectroscopy and multivariate quality-control methods in PVC manufacturing. Analytica Chimica Acta, v.554, issues 1-2, p. 207-217, 2005.

HINITZ, H. J. Inexpensive near-infrared and infrared cell holders for disposable liquid infrared cells. Analytica Chimica Acta, v.51, issue 3, p. 548-553, 1970.

KAROUI, R.; BAERDEMAEKER, J. A review of the analytical methods coupled with chemometric tools for the determination of the quality and identity of dairy products. Food Chemistry, In Press.

MILMAN, B. L. Identification of chemical compounds. Analytica Chimica Acta, v. 24, Issue 6, p. 493-508, 2005. 
PAVIA, D. L.; LAMPMAN, G. M.; KRIZ, G. S. Introduction to spectroscopy: A guide for students of organic chemistry. Philadelphia: Editora Saunders, 1996.

SILVERSTEIN, R. M.; WEBSTER, F. X. Identificação Espectrométrica de Compostos Orgânicos. 6ª.ed. Rio de Janeiro: Editora LTC, 2000.

SKOOG, D. A.; HOLLER, F. J.; NIEMAN, T. A. Princípios de Análise Instrumental,. $5^{a}$. ed. Porto Alegre: Editora Bookman-SBQ, 2002.

The Aldrich Library of FTIR Spectra, 3v, Milwaukee, 1985.

VOGEL, A. I. Análise Química Quantitativa, 6ª . ed. Rio de Janeiro: Editora LTC, 2002.

WHO (World Health Organization). Quality Assurance of pharmaceuticals, v. 1, 1997. 